\title{
BENEFICIAMENTO DO QUARTZO DE TANHAÇU/BA VISANDO A PREPARAÇÃO DE SILÍCIO GRAU METALÚRGICO DE ALTA PUREZA
}

\author{
R. S. S. DIAS ${ }^{1,3}$, E. B. SILVA ${ }^{1,2}$, F. A. N. G. SILVA ${ }^{2}$, F. M. S. GARRIDO ${ }^{2}$, R. S. AMADO² e J. A. SAMPAIO ${ }^{1}$ \\ ${ }^{1}$ Centro de Tecnologia Mineral (CETEM/MCTI) \\ ${ }^{2}$ Instituto de Química/Universidade Federal do Rio de Janeiro \\ ${ }^{3}$ Escola de Química/Universidade Federal do Rio de Janeiro \\ fnogueira@iq.ufrj.br; ebsilva@cetem.gov.br; ranielledias@hotmail.com; chico@iq.ufrj.br; roberto@iq.ufrj.br; \\ jsampaio@cetem.gov.br
}

Artigo submetido em novembro/2013 e aceito em fevereiro/2014

DOI: http://dx.doi.org/10.15628/holos.2014.1820

\section{RESUMO}

Neste trabalho, as etapas de beneficiamento e de caracterização do quartzo de Tanhaçu/BA foram realizadas com o propósito de utilizá-lo como matériaprima para a obtenção de um silício grau metalúrgico (SiGM) com baixo nível de impurezas. A amostra de quartzo, após as etapas de britagem, calcinação seguida de quenching e moagem autógena por $2 \mathrm{~h}$ resultou num produto com elevado teor de $\mathrm{SiO} 2$ (> 99\%), isto é, um aumento de aproximadamente $2 \%$ em relação à amostra original e uma considerável redução nos teores das principais impurezas, boro e fósforo, além de outras como, alumínio, ferro e cálcio, que também comprometem a qualidade do quartzo. A redução dos resultados indica que a amostra de quartzo beneficiada possui potencial para ser utilizada como matéria-prima na produção de SiGM de alta pureza, bem diferente do SiGM convencional.

PALAVRAS-CHAVE: Silício grau metalúrgico, Quartzo, Beneficiamento, Caracterização

\section{ORE DRESSING OF QUARTZ FROM TANHAÇU/BA FOR PRODUCTION OF METALLURGICAL GRADE SILICON (SiGM) WITH HIGH PURITY}

\begin{abstract}
In this paper the steps of ore dressing and characterization of quartz from Tanhaçu/BA were developed for using it as raw material for production of metallurgical grade silicon (SiGM) with low levels of impurities. The quartz sample after steps of crushing, calcining followed by quenching and autogenous grinding for 2 hours resulted in a product with a high $\mathrm{SiO} 2$ content
\end{abstract}

(> 99\%), an increase of nearly $2 \%$ compared to the original sample, and a considerable decrease in the levels impurities, boron and phosphorus, and others as, iron, aluminium and calcium, that also affect the quality of quartz. The results indicate that this quartz has potential to be used in the production of high purity SiGM, quite different from conventional SiGM.

KEYWORDS: Metallurgical grade silicon, Quartz, Ore dressing, Characterization 


\section{INTRODUÇÃO}

O silício grau metalúrgico (SiGM) é a matéria-prima necessária à obtenção do silício grau solar (SiGS) utilizado na produção de células fotovoltaicas (RAJAM, 2011; KIM e KWADWO, 2012). A obtenção do SiGM é feita por redução carbotérmica da sílica em fornos do tipo arco submerso, para produção em larga escala (SERÓDIO, 2009). O conteúdo de $\mathrm{SiO}_{2}$ no produto final deve situarse na faixa de 98,0 a 99,5 \% (SOARES, 2012). O processo baseia-se na redução do quartzo pelo carbono a altas temperaturas, de acordo com a reação, descrita por meio da Equação 1.

$$
\mathrm{SiO}_{2(\mathrm{~s})}+2 \mathrm{C}_{(\mathrm{s})} \rightarrow \mathrm{Si}_{(\mathrm{s})}+2 \mathrm{CO}_{(\mathrm{g})}
$$

O quartzo é um mineral, que apesar do seu elevado teor de $\mathrm{SiO}_{2}$, possui impurezas que contêm os elementos alumínio, manganês, boro, molibdênio, cálcio, níquel, magnésio, zircônio, vanádio, ferro, titânio, cobre, fósforo, cromo e outros (GUSO, 2008).

As impurezas existentes na estrutura do silício grau metalúrgico (SiGM) são responsáveis pelas alterações na condutividade desse material. Essas impurezas provém da própria fonte de sílica, utilizada, ou foram incorporadas ao SiGM durante as etapas de obtenção e processamento. Muitas dessas impurezas podem ser removidas pela solidificação direcional do silício fundido (SAFARIAN, 2012). Contudo, a remoção de boro e de fósforo, por este processo, é difícil e dispendioso devido ao elevado coeficiente de segregação destes elementos nos contornos dos grãos do quartzo (ZHAO, 2011). Além disso, a eliminação parcial destas impurezas torna-se necessária para obtenção de um SiGM de alta qualidade. Portanto, ao utilizar um quartzo natural como matéria-prima, exige-se o desenvolvimento de novos processos de beneficiamento e de purificação do mesmo.

Neste trabalho foram estudados processos químicos e metalúrgicos a serem aplicados ao quartzo do município de Tanhaçu, BA, com o propósito de utilizá-lo, como matéria-prima de elevada pureza, na produção de um SiGM de alta qualidade.

\section{MATERIAIS E MÉTODOS}

Para realização deste estudo, foi realizada a coleta da amostra no município de Tanhaçu, $\mathrm{BA}$, onde há uma jazida de quartzo com elevado grau de pureza. Na etapa de preparação da amostra, efetuou-se o quarteamento da mesma em pilha de homogeneização, da qual retiram-se alíquotas que foram lavadas com água de torneira para remoção de matéria orgânica residual. Após a secagem, as amostras foram cominuídas em um britador de mandíbulas operando em circuito fechado, com uma peneira de abertura de $6 \mathrm{~mm}$, e quarteadas em pilha prismática.

Desse modo, foi realizada a análise granulométrica a úmido em um peneirador vibratório $(684,5 \mathrm{rpm}$ ) equipado com um conjunto de peneiras de abertura desde $2,36 \mathrm{~mm}$ a $37 \mu \mathrm{m}$, segundo a série Tyler. Todas as frações da análise granulométrica foram secas em estufa $\left(80^{\circ} \mathrm{C}\right)$, pesadas e enviadas à caracterização por meio da difração de raios X (DRX). Em paralelo, a amostra, proveniente do ensaio de britagem, foi calcinada a $900^{\circ} \mathrm{C}$ por 30,60 e $90 \mathrm{~min}$. Imediatamente após a calcinação, a amostra foi submetida ao quenching, ou seja, foi retirada do forno estático (mufla) 
e resfriada bruscamente em um recipiente, de aço inox, com água destilada a baixa temperatura $\left(2^{\circ} \mathrm{C}\right)$ e encaminhada à secagem em estufa à temperatura de $80^{\circ} \mathrm{C}$.

Os produtos resultantes da britagem e calcinação foram enviados à análise por emissão ótica por plasma indutivamente acoplado (ICP-OES) e DRX, com o objetivo de verificar se o beneficiamento por meio de modificações na estrutura organizada do silício seguida do rápido resfriamento permite que impurezas sejam removidas da amostra.

A amostra obtida após o quenching foi moída em moinho autógeno por $2 \mathrm{~h}$. Nos ensaios, utilizou-se $1,5 \mathrm{~kg}$ de corpos moedores, constituídos do próprio quartzo com o propósito de minimizar a contaminação. Após essa etapa, as amostras foram enviadas à análise química por ICPOES e por DRX.

Todos os procedimentos experimentais, relativos à preparação da amostra e ao beneficiamento, estão descritos por meio do diagrama de blocos na Figura 1.

\section{RESULTADOS E DISCUSSÃO}

A amostra de quartzo obtida após a britagem $(6 \mathrm{~mm})$ possui, aproximadamente, $45 \%$ das partículas abaixo de $2 \mathrm{~mm}$ e 5\%, abaixo, de $74 \mu \mathrm{m}$ (SOARES et al., 2012). A análise dos resultados indicou que esta amostra é composta essencialmente de quartzo com impurezas de microclínio $\left(\mathrm{KAISi}_{3} \mathrm{O}_{8}\right)$, muscovita $\left((\mathrm{K}, \mathrm{Na})(\mathrm{Al}, \mathrm{Mg}, \mathrm{Fe})_{2}\left(\mathrm{Si}_{3.1} \mathrm{Al}_{0.9}\right) \mathrm{O}_{10}(\mathrm{OH})_{2}\right)$ e calcita $\left(\mathrm{CaCO}_{3}\right)$ (SOARES et al., 2012), inclusive possui um teor de $\mathrm{SiO}_{2}$ de $97,7 \%$, Tabela 1 . Os teores das principais impurezas, isto é, boro, fósforo, alumínio, ferro e cálcio são de 9, 49,1, 3.832, 2.868 e 983 ppm, respectivamente (Tabela 1). Pode-se observar que os resultados conseguidos para esta amostra reportam para um SiGM de baixa qualidade, tornando necessário processos de beneficiamento capaz de purificá-lo.

Após a etapa de calcinação, seguida de quenching, as amostras foram analisadas por ICPOES, cuja análise dos resultados, Tabela 1, indica uma diminuição nos teores de boro, de fósforo e das outras impurezas, em relação à amostra de quartzo sem tratamento térmico.

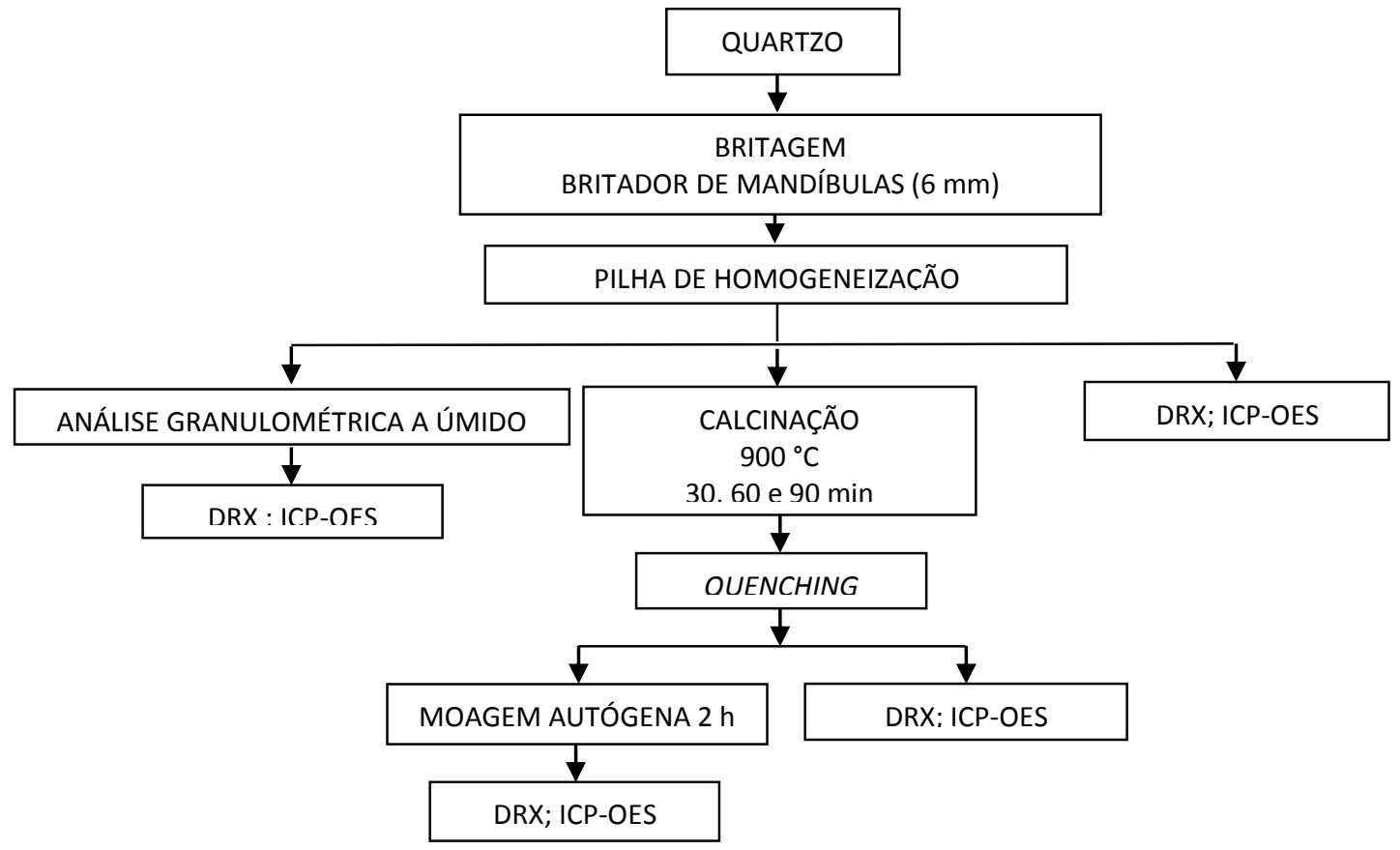

Figura 1 - Diagrama de blocos relativo às etapas de preparação e de beneficiamento do quartzo de Tanhaçu/BA. 
DIAS ET AL. (2014)

Tabela 1 - Resultados das análises de ICP-OES para as amostras de quartzo antes e após o beneficiamento.

\begin{tabular}{|c|c|c|c|c|c|c|c|c|}
\hline \multirow{4}{*}{ Elementos } & \multirow{3}{*}{ LA SiGM } & \multirow{3}{*}{$\begin{array}{l}\text { Quartzo } \\
\text { Britado }\end{array}$} & \multicolumn{3}{|c|}{ Calcinação/Quenching } & \multicolumn{3}{|c|}{ Calcinação/Quenching/Moagem } \\
\hline & & & \multicolumn{6}{|c|}{ Tempo em minutos } \\
\hline & & & 30 & 60 & 90 & 30 & 60 & 90 \\
\hline & \multicolumn{8}{|c|}{ Valores em Percentagens (\%) } \\
\hline \multirow[t]{2}{*}{$\mathrm{SiO}_{2}$} & $98-99,5$ & 97,70 & 98,70 & 99,30 & 99,40 & 99,10 & 99,10 & 99,30 \\
\hline & \multicolumn{8}{|c|}{ Valores em ppm } \\
\hline Boro & 0,2 & 9 & 2 & 6 & 2,3 & 1,7 & 1,9 & 1,8 \\
\hline Fósforo & 10 & 49,1 & 34,4 & 31,1 & 29,8 & 28 & 27,8 & 22,4 \\
\hline Alumínio & 1200 & 3832 & 3343 & 2000 & 2280 & 1907 & 1474 & 1390 \\
\hline Ferro & 1600 & 2868 & 1633 & 1000 & 467 & 726 & 795 & 790 \\
\hline Cálcio & 590 & 983 & 415 & 83,5 & 217 & 147 & 138 & 133 \\
\hline Bário & - & 21,3 & 17,5 & 10,2 & 10,4 & 12,6 & 9,9 & 9,4 \\
\hline Cobalto & - & $<7,0$ & $<7,0$ & $<0,07$ & $<7,0$ & $<7,0$ & $<7,0$ & $<7,0$ \\
\hline Cromo & - & 304 & 47,4 & 31,5 & 8,5 & 8,9 & 9,2 & 11,5 \\
\hline Cobre & - & 9,5 & 6,7 & 3,4 & 3,1 & 2,9 & 2,6 & 3 \\
\hline Potássio & - & 2638 & 2046 & 1100 & 1341 & 1198 & 884 & 818 \\
\hline Lítio & - & 4,7 & 2,5 & $<0,8$ & 17,6 & 1,2 & 1,6 & $<0,4$ \\
\hline Magnésio & - & 877 & 508 & 223 & 158 & 95,7 & 87,2 & 85,3 \\
\hline Sódio & - & 280 & 131 & 41,5 & 220 & 116 & 138 & 118 \\
\hline Estanho & - & $<0,2$ & $<0,2$ & $<0,6$ & $<0,2$ & $<0,2$ & $<0,2$ & $<0,2$ \\
\hline Estrôncio & - & 3,8 & 2,4 & 0,53 & 2,3 & 2,5 & 2,5 & 2,3 \\
\hline Vanádio & - & 3,3 & 2,3 & $<2,0$ & 1,2 & 0,64 & 0,64 & 1 \\
\hline
\end{tabular}

Observa-se que, após o tratamento térmico (calcinação/quenching), os teores de $\mathrm{SiO}_{2}$ aumentam significativamente, isto é, $98,7,99,3$ e 99,4\% para 30, 60 e 90 min, respectivamente. Esses valores são considerados satisfatórios, uma vez que, encontram-se na faixa de valores definidos pela literatura como ideais para a obtenção de um silício SiGM de qualidade (98 a 99,5\%) (SOARES, 2012). Em relação às principais impurezas, boro e fósforo, os ensaios de calcinação (30, 60 e $90 \mathrm{~min}$ ) seguidos do quenching, reduziram o teor desses elementos para 2, 6 e 2,3\% e 34,4, 31,1 e $29,8 \%$, respectivamente. No entanto, após a calcinação, o quenching e a moagem por 2 h, verificou-se uma redução dos teores de boro e de fósforo da ordem de $50 \%$ em relação aos ensaios, para os quais a moagem não foi realizada.

Os resultados obtidos por meio da DRX, Figura 2, corroboram com os descritos na Tabela 1, uma vez que, apesar da DRX não detectar impurezas da ordem de ppm, os picos associados a muscovita e a calcita, após as etapas de beneficiamento, não são mais observados. Como a muscovita e a calcita inserem em suas estruturas cristalinas elementos que são contaminantes na amostra de quartzo estudado, observa-se que, após a calcinação, o quenching e a moagem, há uma redução nos elementos que compõem esses minerais. 


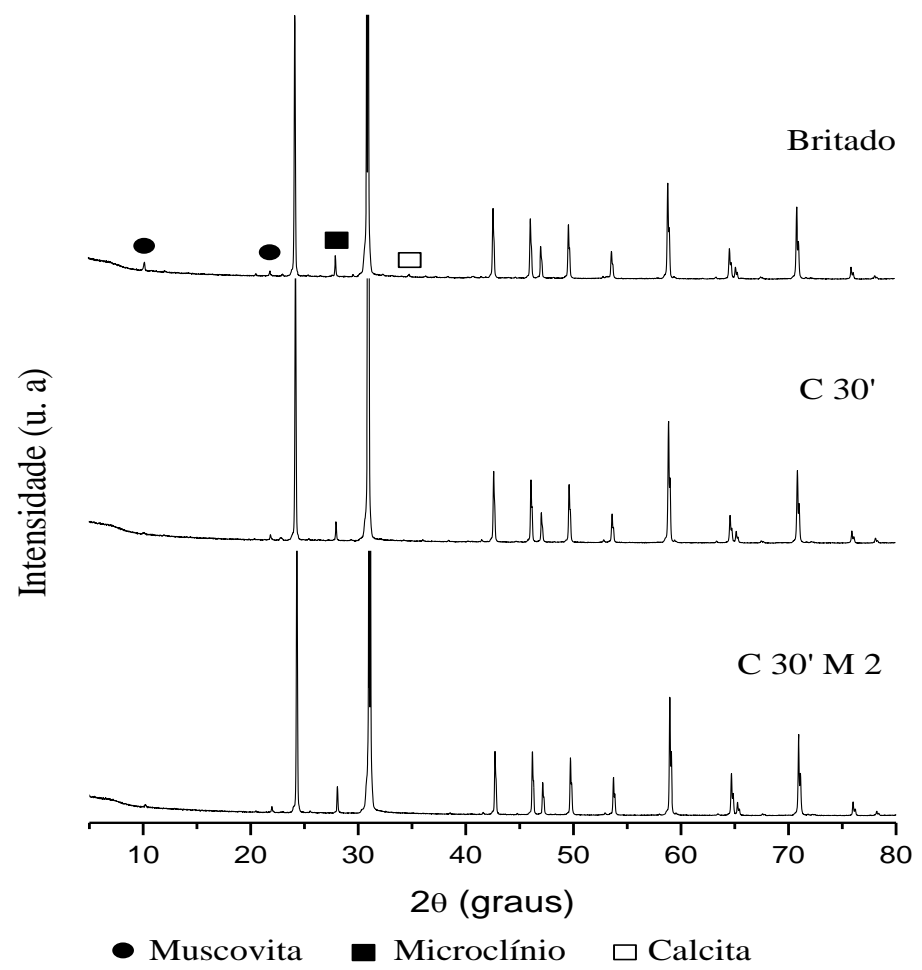

Figura 3 - Difratogramas de raios $X(C o K \alpha)$ para as amostras de quartzo antes e após o beneficiamento. Calcinação por $30 \mathrm{~min}$ (C 30') e calcinação (30 min) seguida de moagem por 2,0 h (C 30' M 2).

\section{CONCLUSÃO}

As etapas de beneficiamento, calcinação seguida de quenching e moagem por $2 \mathrm{~h}$, são indispensáveis à purificação da amostra de quartzo de Tanhaçu/BA, uma vez que a avaliação dos resultados obtidos por meio das análises de DRX e ICP-OES, indicam um significativo aumento no teor de $\mathrm{SiO}_{2}$, de 97,7 para 99,4\%, e uma redução considerável nos teores das principais impurezas, boro e fósforo, e das outras impurezas como alumínio, ferro e cálcio, que também comprometem a qualidade do quartzo. Estudos de lixiviação, bem como calcinações em outras temperaturas, encontram-se em andamento com a finalidade de reduzir ainda mais as impurezas existentes na amostra, para que possa ser utilizada como matéria-prima à produção do SiGM.

\section{AGRADECIMENTOS}

Os autores agradecem ao CNPq pelo auxílio financeiro.

\section{REFERÊNCIAS BIBLIOGRÁFICAS}

1. KIM, E., KWADWO, O. Dissolution Windows for Hydrometallurgical Purification of Metallurgical-Grade Silicon to Solar-Grade Silicon: Eh-pH Diagrams for Fe Silicides. Hydrometallurgy. v.127-128, p. 178-186, 2012.

2. RANJAN, S. et al. Silicon Solar Cell Production. Computers and Chemical Engineering. v.35, p. 1439-1453, 2011.

3. GUSO, P.L. Quartzo. In: Luz. A.B., Lins, F.A.F. Rochas e minerais industriais, $2^{\text {a }}$ Ed., Cap. 31, 
681-722, 990p. CETEM/MCT, Rio de Janeiro, 2008

4. SERÓDIO, L. M.; Estado da arte da obtenção de Silício Grau Solar; Escola Politécnica/UFRJ; Rio de Janeiro, Junho 2009.

5. SOARES, L.G.L., DA SILVA, E.B., GARRIDO, F.M.S, DA SILVA, F.A.N.G., AMADO, R.S., SAMPAIO, J.A., Beneficiamento e caracterização do quartzo para obtenção de silício grau metalúrgico, Holos, Ano 28, v.5, p. 3-10, 2012.

6. SAFARIAN, J., TRANELL, G., TANGSTAD, M., Processes for upgrading metallurgical grade silicon to solar grade silicon, Energy Procedia, v. 20, p. 88-97, 2012.

7. ZHAO, L., WANG, Z., GUO, Z., LI, C., Low-temperature purification process of metallurgical silicon, Transactions of Nonferrous Metals Society of China, v. 21, p. 1185-1192, 2011. 